\title{
The molecular mechanism of fat accumulation changes in Black-Bone chickens with different energy intakes*
}

\author{
R.L. Qi, C. Sun ${ }^{1}$, H.L. Yang, X. Zhao and Z. Tao \\ Northwest A \& F University, College of Animal Science and Technology \\ Yangling 712100, P.R. China
}

(Received 1 July 2011; revised version 27 April 2012; accepted 19 June 2012)

\begin{abstract}
To investigate the molecular mechanism by which diets of different energy levels alter fat accumulation, 120 Black-Bone chickens were divided into 3 groups and fed diets with varying energy levels for six weeks (low: $3.02 \mathrm{Mcal} / \mathrm{kg}$, moderate: $3.22 \mathrm{Mcal} / \mathrm{kg}$, high: $3.42 \mathrm{Mcal} / \mathrm{kg}$ ). The high-energy diet increased the concentration of blood lipids. Furthermore, high-energy intake inhibited the activities of several serum lipases. Histological sections showed over-synthesis of lipids in the livers of chickens fed high-energy diets. Data from western blotting and PCR analyses indicated that key factors for lipogenesis, regulatory transcription factors and fatty acid transporters, were up-regulated, while key factors for lipolysis were down-regulated. Chickens fed low-energy diets showed opposite results. In conclusion, varying energy levels of diets affect fat accumulation in Black-Bone chickens through changed expression of metabolic regulators.
\end{abstract}

KEY WORDS: feed energy, fat, fatty acids, Black-Bone chicken

\section{INTRODUCTION}

Fat synthesis and hydrolysis are both very important in maintaining energy balance in animals. Stable fat metabolism improves the growth and performance of animals (Butler, 1975; Richards et al., 2003). Moreover, efficient fat metabolism improves the quality of animal products such as meat, eggs, milk.

\footnotetext{
* Supported by The National Nature Science Foundation of China, Grant No. 30871785

${ }^{1}$ Corresponding author: e-mail: sunchao2775@163.com
} 
In contrast, irregular fat metabolism leads to disorders such as obesity, hypertension, hyperlipaemia, insulin resistance, and others.

Fat metabolism involves ingenious physiological and biochemical reactions. Excess energy, the majority of which comes from food, is stored in adipocytes in the form of triglycerides and released for use during starvation or strenuous exercise. A large number of hormones, enzymes, and protein factors in different tissues are responsible for controlling every step of fat metabolism and energy balance. Fatty acid synthase (FAS) and acetyl-CoA carboxylase (ACC) are key factors for lipogenesis, while adipose triglyceride lipase (ATGL) and lipoprotein lipase (LPL) are factors for lipolysis (Richards, 2003; Richards et al., 2003). Accumulated studies have demonstrated that nutritional ingredients in food have noticeable effects on the expression and function of fat metabolism regulators (Jump, 1999; Wen et al., 2007).

The objective of our study was to evaluate the effects of varying dietary energy levels on the fat metabolism of Black-Bone chickens. The growth of commercial Black-Bone chickens is as fast as that of broiler chickens. In addition, Black-Bone chicken has more economic and nutritional value. Few studies on this breed of chicken have been done, however. In the present study, dietary energy was set to three different levels while dietary protein levels were maintained constant. Chickens were given different dietary energy levels for a specified period of time to analyse changes in the expression of metabolic regulators.

\section{MATERIAL AND METHODS}

\section{Experimental design}

One hundred and twenty one-day-old male Black-Bone chicks (Gallus gallus domesticus) were obtained and housed in a clean room with constant lighting. A commercial diet and water were provided ad libitum. When the chickens reached 28 days of age, they were randomly divided into 3 groups and fed diets with varying energy levels without changes in protein content (group E1, low energy: $3.02 \mathrm{Mcal} / \mathrm{kg}$; group E2, moderate energy, $3.22 \mathrm{Mcal} / \mathrm{kg}$; group E3, high energy: $3.42 \mathrm{Mcal} / \mathrm{kg}$ ). The diet formulation was based on maize and soyabean meal and met NRC (1994) nutrient requirements for broiler chickens (Table 1). To regulate the dietary energy levels, we changed the percentage of maize, soyabean meal, and vegetable oil in the diets.

At 70 days of age, 8 chickens were selected randomly from each group and bled by cardiac puncture. The blood was collected to obtain plasma by centrifugation at $1500 \mathrm{~g}$ for $10 \mathrm{~min}$. The chickens were killed after bleeding to collect abdominal fat 
pads and livers for gene expression and protein level analyses. The tissue samples were snap-frozen in liquid nitrogen as soon as they were obtained and stored at $-80^{\circ} \mathrm{C}$ until analysis.

Table 1. Compositions and nutrient levels for diets

\begin{tabular}{lccrlrcc}
\hline Composition, \% & E1 $^{1}$ & E2 $^{1}$ & E3 $^{1}$ & \multicolumn{1}{c}{ Nutrition level } & E1 $^{1}$ & E2 $^{1}$ & E3 $^{1}$ \\
\hline Maize & 59.3 & 58 & 53.2 & Crude protein, \% & 20.3 & 20.3 & 20.3 \\
Soyabean meal & 26.8 & 26.3 & 27.3 & Metabolizable energy, Mcal/kg & 3.02 & 3.22 & 3.42 \\
Fish meal & 6.5 & 6.5 & 6.5 & Ca, \% & 0.95 & 0.91 & 0.91 \\
CaHCO $_{3}$ & 1.2 & 0.7 & 0.8 & Available phosphorus, \% & 0.41 & 0.43 & 0.5 \\
Limestone & 1.3 & 1.1 & 1.05 & Lysine, \% & 1.13 & 1.09 & 1.18 \\
Salt & 0.25 & 0.25 & 0.2 & Methionine, \% & 0.41 & 0.38 & 0.44 \\
Vegetable oil & 3.5 & 6 & 9.8 & NaCL, \% & 0.37 & 0.37 & 0.38 \\
Microelements & 1 & 1 & 1 & Crude fat, \% & 2.47 & 2.31 & 1.81 \\
Methionine & 0.05 & 0.05 & 0.05 & Crude ash, \% & 5.75 & 5.32 & 4.47 \\
Lysine & 0.1 & 0.1 & 0.1 & & & & \\
\hline
\end{tabular}

note - provided per kg of diet; IU: vit. A 10000, vit. $\mathrm{D}_{3} 2600$, vit. $\mathrm{E} 20$; mg: vit. $\mathrm{K}_{3} 2$, vit. $\mathrm{B}_{1} 1.6$, vit. $\mathrm{B}_{2} 6$, vit. $\mathrm{B}_{6} 3$, vit. $\mathrm{B}_{12} 0.014$, pantothenic acid 20 , niacin 30 , folic acid 0.8 , biotin 0.12 , choline 500 , $\mathrm{Cu}(\mathrm{CuSO} 4 \cdot 5 \mathrm{H} 2 \mathrm{O})$ 8, Zn(ZnSO4-7H2O) 40, Fe(FeSO4·7H2O)80, I(KI) 0.35, Se(Na2SeO3) 0.15

${ }^{1}$ E1 - low energy; E1 - moderate energy; E3 - high energy

\section{Blood lipids and enzyme activities}

The concentrations of triglycerides (TG), total cholesterol (TC), free fatty acids (FFAs), high-density lipoprotein cholesterol (HDL-C), and low-density lipoprotein cholesterol (LDL-C) in serum samples were determined by an automatic biochemical analyzer using colorimetric methods. In addition, the activities of lipoprotein lipase (LPL), hepatic lipase (hL), and serum lipases (LPS) were assayed using corresponding kits.

\section{Histological examination}

The morphology of the chicken livers was observed by histological sectioning. At 60 days of age, 3 chickens were randomly selected from each group and slaughtered immediately. The liver of each chicken was collected and fixed with $4 \%$ neutral formaldehyde, dehydrated in an alcohol gradient, and then sectioned after embedding in paraffin. The sections were stained with haematoxylin-eosin and observed under a microscope $(10 \times)$.

\section{Real-time PCR}

The PCR was conducted as previously described (Sun et al., 2011). Total RNA was isolated from frozen abdominal fat pads and livers using an RNAiso Plus Kit (TaKaRa, China). Reverse transcription was performed for first-strand cDNA 
synthesis using a Primescript RT reagent kit (TaKaRa, China). Real-time PCR was performed with the iQ5 System (BioRad, USA). Expression of genes was computed relative to that of $\beta$-actin, and the normalized values were expressed as a ratio. The values for group E2 were defined as 1.0. The oligonucleotide sequences of PCR primers are shown in Table 2.

Table 2. PCR parameter of primers

\begin{tabular}{|c|c|c|c|}
\hline Gene & Primer sequences $\left(5^{\prime} \rightarrow 3^{\prime}\right)$ & Gene ID & $\mathrm{Tm},{ }^{\circ} \mathrm{C}$ \\
\hline \multirow[t]{2}{*}{$\overline{\beta-a c t i n}$} & F: ACCACAGCCGAGAGAGAAAT; & NM_205518 & 58.0 \\
\hline & R: GACCTGACCATCAGGGAGTT & & \\
\hline \multirow[t]{2}{*}{ FAS } & F: AAGGAGGAAGTCAACGGG & NM_205155.2 & 53.5 \\
\hline & R: GATGGTGAGGAGTCGGAT & & \\
\hline \multirow[t]{2}{*}{$L P L$} & F: TGAAGGACCTTATCGCATTGC & NM_205282.1 & 55.6 \\
\hline & R: GCATGGGAAGCATTTTGTTGT & & \\
\hline \multirow[t]{2}{*}{$A C C$} & F: CCTACCAAGACTCCCTAT & NM_205505.1 & 51.2 \\
\hline & R: GTTTCTACGGCAACTACTC & & \\
\hline \multirow[t]{2}{*}{$A T G L$} & F: TGGAACTGTCTCGTGGG & EU_240627.2 & 50.5 \\
\hline & R: CTACTGTGGGCTGATACCT & & \\
\hline \multirow[t]{2}{*}{$P P A R \gamma$} & F: ACCACTCGCATTCCTTTGAC & NM_001001460 & 60.2 \\
\hline & R: CCACAGACTCGGCACTCAAT & & \\
\hline \multirow[t]{2}{*}{ PPAR $\alpha$} & F: CAGAATAAGGAAGCCGAAGT & NM_001001464 & 55.4 \\
\hline & R: AATGATGGCAGCGACAAA & & \\
\hline \multirow[t]{2}{*}{ FATP-1 } & F: CGGTGCTGTTACGAGTGA & NM_001039602 & 61.5 \\
\hline & R: CACGGCGTTGGAATACTT & & \\
\hline \multirow[t]{2}{*}{$F A B P$} & F: ATGTGCGACCAGTTTGTG & NM_204290 & 50.8 \\
\hline & R: TTTGCCATCCCACTTCTG & & \\
\hline \multirow[t]{2}{*}{ FAT/CD36 } & F: CTGGGAAGGTTACTGCGATTT & DQ323177 & 52.9 \\
\hline & R: TTCACGGTCTTACTGGTCTGG & & \\
\hline
\end{tabular}

Western blot analysis

The adipose tissues were homogenized and lysed for $30 \mathrm{~min}$ at $4{ }^{\circ} \mathrm{C}$ using a lysis buffer containing $50 \mathrm{mM}$ Tris ( $\mathrm{pH} 7.4$ ), $150 \mathrm{mM} \mathrm{NaCl}, 1 \% \mathrm{NP}-40$, and $0.1 \%$ SDS. After centrifugation at $12,000 \mathrm{~g}$ for $10 \mathrm{~min}$ at $4{ }^{\circ} \mathrm{C}$, the total protein extracts were separated using 12\% SDS-polyacrylamide gel electrophoresis (PAGE) and transferred to polyvinylidene membranes. The membranes were blocked with $5 \%$ nonfat milk in Tris-buffered saline containing $0.1 \%$ Tween 20 (TBST) at room temperature for $2 \mathrm{~h}$, and probed overnight with primary antibodies at $4^{\circ} \mathrm{C}$ (anti-PPAR $\gamma, 1: 250$; anti-ATGL, 1:400; anti-FAS, 1:300, and anti- $\beta$-actin, 1:500; Santa Cruz, USA). After washing with TBST, the membranes were probed with a horseradish peroxidase-labeled secondary antibody (1:5000, Santa Cruz, USA) at room temperature for $1.5 \mathrm{~h}$. Blots were visualized with a chemiluminescence reagent (Millipore, USA) using an imaging system (BioRad, USA). 


\section{Statistical analyses}

The SPSS 13.0 statistics software package was used for one-way ANOVA and $t$-tests. Data were presented as means $\pm \mathrm{SEM}$ and differences were considered statistically significantly at $\mathrm{P}<0.05$ or $\mathrm{P}<0.01$.

\section{RESULTS}

\section{Body weight, feed intake and body fat}

There were no differences in body weight (BW) between the three groups at the beginning of experiment $(\mathrm{P}>0.05)$. BW significantly increased with time, however, in the high energy group. On days 49 and 70, the chickens in group E3 had the largest average BW $(\mathrm{P}<0.01)$, while the $\mathrm{E} 1$ group had the lowest $(\mathrm{P}<0.01)$. In addition, chickens in the E3 group showed the highest average daily gain and lowest feed-to-gain ratio $(\mathrm{P}<0.01)$, whereas group E1 showed the opposite results (Table 3).

Table 3. Body weight (BW), feed intake and conversion, and fat accumulation

\begin{tabular}{lccc}
\hline Parameters & $\mathrm{E}^{1}$ & $\mathrm{E} 2^{1}$ & $\mathrm{E}^{1}$ \\
\hline 28 day BW, g & $335.73 \pm 40.26^{\mathrm{A}}$ & $340.19 \pm 35.40^{\mathrm{A}}$ & $337.21 \pm 30.84^{\mathrm{A}}$ \\
49 day BW, g & $841.61 \pm 58.01^{\mathrm{C}}$ & $971.97 \pm 73.81^{\mathrm{B}}$ & $1045.76 \pm 6912^{\mathrm{A}}$ \\
70 day BW, g & $1469.17 \pm 79.34^{\mathrm{C}}$ & $1668.16 \pm 38.97^{\mathrm{B}}$ & $1717.83 \pm 61.86^{\mathrm{A}}$ \\
$\mathrm{ADG}, \mathrm{g}$ & $26.37 \pm 4.24$ & $30.88 \pm 3.79^{\mathrm{B}}$ & $32.80 \pm 3.20^{\mathrm{A}}$ \\
Feed/Gains & $2.43 \pm 0.36^{\mathrm{A}}$ & $2.28 \pm 0.41^{\mathrm{B}}$ & $2.25 \pm 0.50^{\mathrm{C}}$ \\
\hline Material & $\mathrm{E} 1^{1}$ & $\mathrm{E} 2^{1}$ & $\mathrm{E} 3^{1}$ \\
\hline Breast IMF/breast & $1.46 \pm 0.13^{\mathrm{C}}$ & $1.60 \pm 0.10^{\mathrm{AB}}$ & $1.74 \pm 0.21^{\mathrm{A}}$ \\
Leg IMF/leg & $4.66 \pm 0.30^{\mathrm{C}}$ & $5.89 \pm 0.25^{\mathrm{AB}}$ & $6.08 \pm 0.17^{\mathrm{A}}$ \\
AMFW/BW & $1.67 \pm 0.14^{\mathrm{C}}$ & $2.23 \pm 0.20^{\mathrm{B}}$ & $2.52 \pm 0.25^{\mathrm{A}}$ \\
Subcutaneous fat, mm & $2.33 \pm 0.14^{\mathrm{C}}$ & $2.67 \pm 0.13^{\mathrm{B}}$ & $2.90 \pm 0.16^{\mathrm{A}}$ \\
\hline note -data are expressed as the mean \pm SEM, n=8. In the same line, means with different letters \\
are different $(\mathrm{P}<0.05)$, means with same letters are not significantly different $(\mathrm{P}>0.05) . \mathrm{BW}-$ body \\
weight; ADG - average daily gain; IMF - intramuscular fat; AMFW - abdominal fat pad weight \\
${ }^{1}$ see Table 1
\end{tabular}

After the chickens were sacrificed, fat accumulation in the body was determined. The E3 group chickens showed the highest body fat, while the E1 group chickens showed the least (Table 3). The weight of intramuscular fat (IMF) and the abdominal fat pad, as well as the thickness of subcutaneous fat significantly increased with increasing energy intake. 


\section{Blood lipids and enzyme activities}

Changes in the concentrations of blood lipids partly reflected the metabolic trends in the birds. Table 4 showed that the varying dietary energy yielded changes in the blood lipid concentrations of chickens. With increasing energy intake, the concentrations of TG, TC, HDL-C, and LDL-C markedly increased, while those of FFAs decreased. In addition, enzymes related to lipid hydrolysis exhibited higher activities in chickens fed the lower-energy diet. These results showed that higher energy intake produced more lipids that flow into the circulatory system. In contrast, lower energy intake produced more FFAs that are released for energy consumption by other organs.

Table 4. Blood lipids and enzyme activity

\begin{tabular}{llrrr}
\hline Indices & & \multicolumn{1}{c}{$\mathrm{E}^{1}$} & \multicolumn{1}{c}{ E2 $^{1}$} & \multicolumn{1}{c}{$\mathrm{E} 3^{1}$} \\
\hline TG & $\mathrm{mmol} / 1$ & $0.26 \pm 0.07^{\mathrm{C}}$ & $0.33 \pm 0.06^{\mathrm{B}}$ & $0.39 \pm 0.04^{\mathrm{A}}$ \\
TC & $\mathrm{mmol} / 1$ & $3.49 \pm 0.05^{\mathrm{C}}$ & $3.85 \pm 0.04^{\mathrm{B}}$ & $4.17 \pm 0.09^{\mathrm{A}}$ \\
HDL-C & $\mathrm{mmol} / 1$ & $1.34 \pm 0.12^{\mathrm{C}}$ & $1.37 \pm 0.17^{\mathrm{B}}$ & $1.40 \pm 0.11^{\mathrm{A}}$ \\
LDL-C & $\mathrm{mmol} / 1$ & $2.38 \pm 0.09^{\mathrm{C}}$ & $2.41 \pm 0.13^{\mathrm{B}}$ & $2.69 \pm 0.10^{\mathrm{A}}$ \\
FFA & $\mathrm{mmol} / 1$ & $0.67 \pm 0.13^{\mathrm{A}}$ & $0.54 \pm 0.14^{\mathrm{B}}$ & $0.52 \pm 0.11^{\mathrm{C}}$ \\
LPS & $\mathrm{U} / 1$ & $129.51 \pm 1.25^{\mathrm{A}}$ & $104.24 \pm 1.77^{\mathrm{B}}$ & $75.69 \pm 1.6^{\mathrm{C}}$ \\
LPL & $\mathrm{U} / \mathrm{ml}$ & $2.47 \pm 0.35^{\mathrm{A}}$ & $2.42 \pm 0.41^{\mathrm{A}}$ & $2.10 \pm 0.25^{\mathrm{B}}$ \\
HL & $\mathrm{U} / \mathrm{ml}$ & $1.58 \pm 0.13^{\mathrm{A}}$ & $1.44 \pm 0.18^{\mathrm{B}}$ & $1.32 \pm 0.11^{\mathrm{C}}$ \\
\hline
\end{tabular}

note - data are expressed as the mean \pm SEM, $n=8$. In the same row, means with different letters are significantly different $(\mathrm{P}<0.05 \%)$, means with same letters are not significantly different $(\mathrm{P}>0.05 \%)$ ${ }^{1}$ see Table 1

\section{Liver histology}

The liver is the most important origin for lipogenesis in birds and accounts for $95 \%$ of de novo fatty acid synthesis in young chickens (OHea and Leveille, 1969). Several significant differences were observed in the liver sections of each group under haematoxylin-eosin (H\&E) staining. Figure 1 shows that both the volume and number of fat droplets significantly increased in the livers of chickens in group E3 compared with groups E1 and E2 (original magnification $\times 100$, black spots are cell nuclei, white spots are fat droplets; Figure 1).

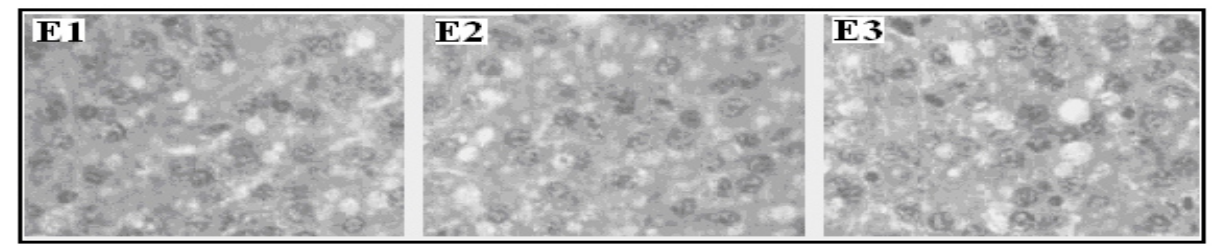

Figure 1. Photomicrographs of sections of chicken liver. H\&E staining, original magnification $\times 10$. Black spots indicated cell nuclei and white spots indicated fat droplets 
Gene expression and levels of proteins associated with lipid metabolism

FAS and ACC catalyze the synthesis of fatty acids, and are important enzymes in lipogenesis and fat accumulation (Smith et al., 2003; Tong, 2005; Maier et al., 2008). The present results show that with increasing energy level, the expression of FAS and ACC mRNA increased in adipose tissue (Figure 2A) and the liver (Figure 2B). Peroxisome proliferator-activated receptors (PPARs) are a group

A

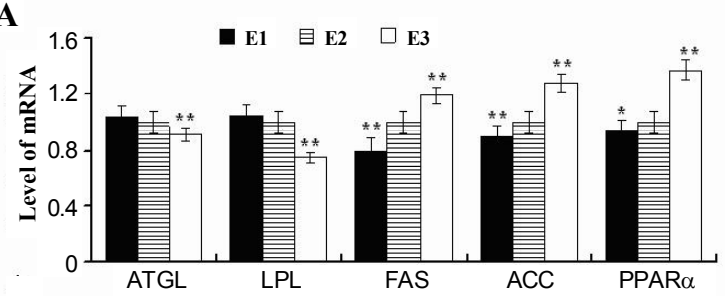

B

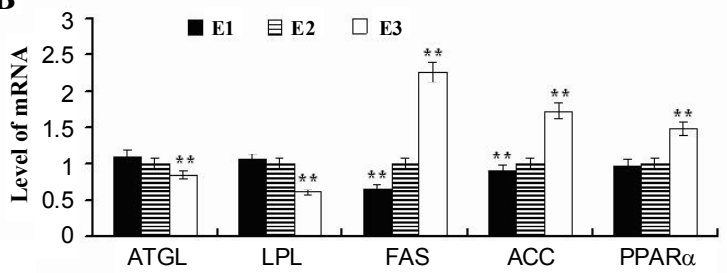

C

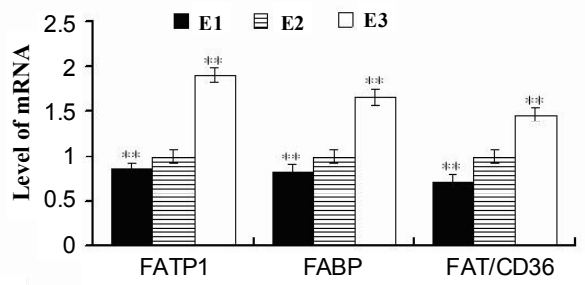

D 3.50

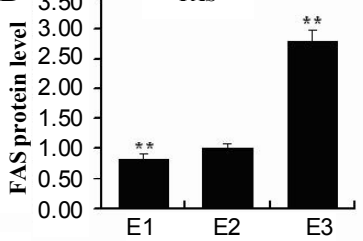

E 1.20, ATGL
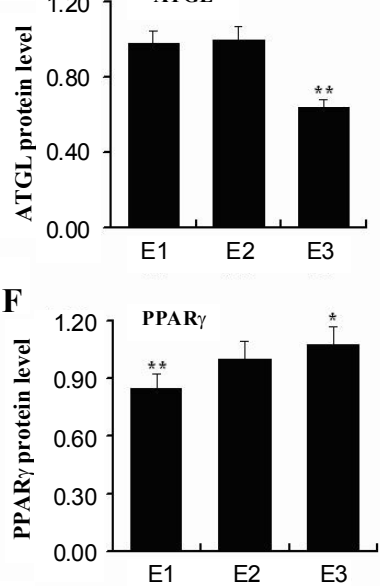

G

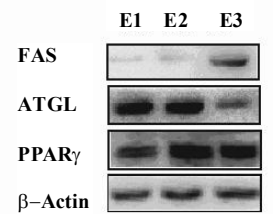

Figure 2. The mRNA expression and protein level of regulators involved in fat metabolism and FFAs transport. A - mRNA expressions of fat metabolism regulators were in adipose tissue; B - mRNA expressions of fat metabolism regulators were in liver; $\mathrm{C}$ - mRNA expressions of free fatty acids transporters were in adipose tissue. Their expression levels were calculated relative to that of the $\beta$-actin mRNA level. The protein levels of FAS (D), ATGL (E) and PPAR $\gamma(\mathrm{F})$ were normalized to that of $\beta$-Actin. Quantification analysis through detected the optical density of blots $(G)$ by using a Quantity One software. Values are means \pm SEM; $n=5$. The value of E2 group defined as 1.0, compared with E2 group, ** means $\mathrm{P}<0.01$, * means $\mathrm{P}<0.05$ 
of nuclear receptor proteins acting as transcription factors that regulate the expression of genes involved in energy homeostasis (Everent et al., 2000). PPAR $\alpha$ is an important member of this protein family and activated PPAR $\alpha$ may facilitate stearolysis (Yoon, 2009). In contrast to PPAR $\alpha$, PPAR $\gamma$ is mainly responsible for adipocyte differentiation and lipid synthesis (Konig et al., 2009). Our data show that the expression of FAS exhibited a similar trend as that of PPAR $\alpha$ in the liver. PPAR $\gamma$ in group E3 had the highest expression and no significant differences were observed between groups E1 and E2. LPL hydrolyses lipids in lipoproteins, such as chylomicrons and very low-density lipoproteins, into free fatty acids and monoacylglycerols (Mead et al., 2003). ATGL is a crucial lipase that catalyzes triglyceride hydrolysis and has a key role in lipid droplet degradation (Raben et al., 2006; Smirnova et al., 2006). Compared with group E2, there was a marked decrease in the expression of ATGL $(\mathrm{P}<0.01)$ and LPL $(\mathrm{P}<0.01)$ mRNAs in group E3. No significant differences between groups E1 and E2 were observed.

The protein levels of PPAR $\gamma$, FAS, and ATGL in adipose tissue were detected by western blot analysis. Consistent with the mRNA levels, high-energy intake $(3.42 \mathrm{Mcal} / \mathrm{kg}$ ) significantly increased the levels of PPAR $\gamma$ and FAS and decreased that of ATGL (Figure 2D-G).

It was initially believed that FFAs entered cells merely by diffusion through the phospholipid bilayers. Increasing evidence has shown, however, that aside from this diffusion component, the intestine, liver, heart, adipose tissue, and other organs possess a saturable and complete FA transport system that is controlled by several proteins: fatty acid transport protein 1 (FATP1), fatty acid binding protein (FABP), and fatty acid translocase (FAT) (Stahl et al., 2001; Pohl et al., 2004; Stahl, 2004). Our results show that FATP1, FABP, and FAT had the highest mRNA levels in group E3 (Figure 2C) and that the level of their expression in group E2 was significantly higher than in group E1.

\section{DISCUSSION}

It is well known that body fat stores provide energy to other organs. Moreover, adequate fat can improve the quality of animal products. In recent years, some studies have found that white adipose tissue exhibits an endocrine function and secretes such protein factors as adiponectin and leptin (Zhang et al., 1994; Renaldi et al., 2009). Thus, given that the adipose tissue plays an important role in the body, research on fat-related metabolism is important and valuable.

In the present study we showed that a high energy intake markedly increased body fat accumulation in chickens even though consumption of feed decreased. 
In addition, the concentrations of TC, HDL-C, LDL-C, and TG increased in the serum of chickens fed the high-energy diet, whereas that of FFAs decreased. These results indicate that higher energy intake results in more lipid production and more fat accumulation in the body. Similar studies found that dietary energy has significant effects on the lipid content of chukar blood (Özek and Bahtiyarca, 2004). Nonetheless, another study suggested that varied dietary energy levels $(10.03,11.00$, and $11.85 \mathrm{MJ} / \mathrm{kg}$ ) had no significant effect on the concentration of $\mathrm{TC}, \mathrm{TG}$, and lipoproteins in goose blood (Ma et al., 2006). The difference between these results is probably due to differences in the species or dietary energy gradients in the experiments. Our data also revealed that lipolysis was attenuated in chickens fed the high-energy diet. Similar results have been reported showing that a high-fat diet decreased mRNA expression and LPL activity in swine adipose tissue (Pettigrew and Esnaola, 2001).

In the present study, the expression of both FAS and ACC mRNA increased significantly in chickens in group E3 (3.42 Mcal $/ \mathrm{kg})$. Therefore, de novo synthesis of fatty acids regulated by FAS and ACC was favoured and resulted in higher fat synthesis and accumulation in the body. In contrast, the expression of both ATGL and LPL mRNA decreased in group E3. This result supports the idea that a high-energy diet has an inhibitory effect on lipolysis. Changes in the levels of FAS and ATGL proteins were consistent with the changes in mRNA expression. In addition, changes in the mRNA expression of FA transporters under different energy intakes were observed. The results suggest that the protein-mediated FFA transport system was more efficient in chickens with a high-energy intake. Some studies have found that rapid diffusion of FFAs through the phospholipid bilayer occurs when they are present at high concentrations, however, the protein-mediated FA transport system produced a marked effect at low substrate concentrations (Chabowski et al., 2006; Thompson et al., 2010).

\section{CONLUSIONS}

In summary, varying dietary energy levels have significant effects on the dynamic balance of fat metabolism in chicken through changing the expression of metabolic regulators, such as fatty acid synthase, adipose triglyceride lipase, and peroxisome proliferator-activated receptor. High-energy intake $(3.42 \mathrm{Mcal} / \mathrm{kg})$ significantly increased fat accumulation in Black-Bone chickens via the up-regulation of lipogenetic gene expression and the down-regulation of lipolytic gene expression. All of the changes observed during high-energy intake were opposite to those observed during low-energy intake $(3.02 \mathrm{Mcal} / \mathrm{kg}$ ). In addition, the proteinmediated fatty acid transport system was more efficient in the adipose tissue of chickens fed the high-energy diet. 


\section{REFERENCES}

Butler E.J., 1975. Lipid metabolism in the fowl under normal and abnormal circumstances. Proc. Nutr. Soc. 34, 29-34

Chabowski A., Górski J.I., Bonen A., 2006. Regulation of fatty acid transport: from transcriptional to posttranscriptional effects. Naunyn Schmiedeberg's Arch. Pharmacol. 373, 259-263

Everent L., Galli A., Grabb D., 2000. The role of PPARs in health and disease. Liver 20, 191-199

Jump D.B., 1999. Regulation of gene expression by dietary fat. Ann. Rev. Nutr. 19, 63-90

Konig B., Koch A., Spielmann J., Christian H., Frank H., Gabriele S., Klaus E., 2009. Activation of PPAR $\alpha$ and PPAR $\gamma$ reduces triacylglycerol synthesis in rat hepatoma cells by reduction of nuclear SREBP-1. Eur. J. Pharmacol. 605, 23-30

Ma Y.Q., Yang J.M., Xia Z.S., 2006. Effects of different diets on performance and nutrient utilization of Hepu geese. Chinese J. Anim. Nutr. 18, 192-196

Maier T., Leibundgut M., Ban N., 2008. The crystal structure of a mammalian fatty acid synthase. Science 321, 1315-1322.

Mead J.R., Irvine S.A., Ramji D.P., 2003. Lipoprotein lipase: structure, function, regulation, and role in disease. J. Mol. Med. 80, 753-769

NRC, 1994. Nutrient Requirements of Poultry. ${ }^{\text {th }}$ revised Edition. National Academy Press. Washington, DC

O'Hea E.K., Leveille G.A., 1969. Lipid biosynthesis and transport in the domestic chick (Gallus domesticus). Comp. Biochem. Physiol. 30, 149-159

Özek K., Bahtiyarca Y., 2004. Effects of sex and protein and energy levels in the diet on the blood parameter of the chukar partridge. Brit. Poultry Sci. 45, 290-293

Pettigrew J.E., Esnaola M.A., 2001. Swine nutrition and pork quality. Anim. Sci. 79, 316-342

Pohl J., Ring A., Hermaann T., Stremmel W., 2004. Role of FATP in parenchymal cell fatty acid uptake. Biochim. Biophys. Acta 1686, 1-6

Raben D.M., Baldassare J.J., 2005. A new lipase in regulating lipid mobilization: hormone-sensitive lipase is not alone. Trends Endocrinol. Metab. 16, 35-36

Renaldi O., Pramono B., Sinorita H., Purnomo L.B., Asdie R.H., Asdie A.H., 2009. Hypoadiponectinemia: a risk factor for metabolic syndrome. Acta Med. Indonesia 41, 20-24

Richards M., 2003. Genetic regulation of feed intake and energy balance in poultry. Poultry Sci. 82, 907-916

Richards M., Poch S., Coon C., Rosebrough R., Ashell C., McMurtry J., 2003. Feed restriction significantly alters lipogenic gene expression in broiler breeder chickens. J. Nutr. 133, 707-715

Smirnova E., Goldberg E.B., Makarova K.S., Lin L., Brown W.J., Jackson C.L., 2006. ATGL has a key role in lipid droplet/adiposome degradation in mammalian cells, EMBO Rep. 7, 106-113

Smith S., Witkowski A., Joshi A.K., 2003. Structural and functional organization of the animal fatty acid synthase. Prog. Lipid Res. 42, 289-317

Stahl A., 2004. A current review of fatty acid transport proteins (SLC27). Pflügers Arch. 447, 722727

Stahl A., Gimeno R.E., Tartaglia L.A., Lodish H.F., 2001. Fatty acid transport proteins: acurrent view of a growing family. Trends Endocrinol. Metab. 12, 269-273

Sun C., Qi R.L., Wang L., Yan J., Wang Y., 2011. p38 MAPK regulates calcium signal-mediated lipid accumulation through changing VDR expression in primary preadipocytes of mice. Mol. Biol. Rep DOI: 10.1007/s11033-011-1084-8 (online)

Thompson B.R., Lobo S., Bernlohr D.A., 2010. Fatty acid flux in adipocytes: The in's and out's of fat cell lipid trafficking. Mol. Cell. Endocrinol. 318, 24-33 
Tong L., 2005. Acetyl-coenzyme A carboxylase: crucial metabolic enzyme and attractive target for drug discovery. Cell. Mol. Life Sci. 62, 1784-803

Yoon M., 2009. The role of PPAR $\alpha$ in lipid metabolism and obesity: Focusing on the effects of estrogen on PPAR $\alpha$ actions. Pharmacol. Res. 60, 151-159

Wen S., Shailja P., Zaixin Y., 2007. Effects of rosiglitazone and high fat diet on lipase/esterase expression in adipose tissue. Biochim. Biophys. Acta 1771, 177-184

Zhang Y., Proenca R., Maffie M., Barone M., Leopold L., Friedman J., 1994. Positional cloning of the mouse obese gene and its human homologue. Nature 372, 425-432 